\title{
Investigation of a New Voltage Balancing Circuit for Parallel-connected Offshore PMSG-based Wind Turbines
}

\author{
Ahmed A. Elserougi*, Otavio Bertozzi ${ }^{\dagger}$, Ahmed M. Massoud ${ }^{\ddagger}$ and Shehab Ahmed ${ }^{\dagger}$ \\ ${ }^{*}$ Department of Electrical Engineering, Alexandria University, Alexandria, Egypt \\ ${ }^{\dagger}$ CEMSE Division, King Abdullah University of Science and Technology, Thuwal, Saudi Arabia \\ ${ }^{\ddagger}$ Department of Electrical Engineering, Qatar University, Doha, Qatar
}

\begin{abstract}
Parallel connection of wind turbines (WTs) is beneficial in high-power applications. For successful operation of parallel WT-based energy conversion systems, a well-regulated voltage is needed at the collection point. Due to wind speed variation, the generated voltage from each WT may differ from one to another. Conventional solutions use regulating converters with full power rating. In this paper, a new concept is presented which depends on using fully-rated uncontrolled rectifier bridges for AC-DC conversion, and partially-rated fully-controlled bridge rectifiers which are used as voltage tuners to guarantee the flow of desired maximum power point DC currents through the parallel connected branches. The proposed system is simple, cost effective, reliable and efficient. The main drawback of the proposed system is the critical need for filters and VAR compensators on the AC side to ensure acceptable performance of the WT generator. Also, smoothing reactors are needed on the DC side for filtering of the transmitted DC current. A simulation model has been built to validate the proposed concept, and the simulation results show the effectiveness of the approach.
\end{abstract}

Index Terms-Balancing circuit, Offshore, PMSG, Wind Turbines

\section{NOMENCLATURE}

$\begin{array}{ll}\text { AC } & \text { Alternating Current. } \\ \text { B2B } & \text { Back-to-Back. } \\ \text { DC } & \text { Direct Current. } \\ \text { DFIG } & \text { Doubly-Fed Induction Generator. } \\ \text { GSC } & \text { Grid Side Converter. } \\ \text { HVDC } & \text { High Voltage Direct Current. } \\ \text { IGBT } & \text { Insulated Gate Bipolar Transistor. } \\ \text { MPPT } & \text { Maximum Power Point Tracking. } \\ \text { PI } & \text { Proportional-Integral. } \\ \text { PLL } & \text { Phase-Locked Loop. } \\ \text { PMSG } & \text { Permanent Magnet Synchronous Generator. } \\ \text { RMS } & \text { Root Mean Square. } \\ \text { VSC } & \text { Voltage Source Converter. } \\ \text { WECS } & \text { Wind Energy Conversion System. } \\ \text { WT } & \text { Wind Turbine. }\end{array}$

\section{INTRODUCTION}

W IND energy is amongst the most promising renewable energy sources. Generation capacity has been consistently increasing in the past years. Reports from the Global Wind Energy Council (GWEC) indicate that since 2014, more than $50 \mathrm{GW}$ of wind energy capacity is installed annually, with $51.3 \mathrm{GW}$ installed in 2018 alone, summing up to more than $590 \mathrm{GW}$ total worldwide [1]. In 2019, the new installed capacity was of $60.4 \mathrm{GW}$ [2].

The wind energy market is commonly divided in two categories: onshore and offshore. Although the latter amounts to $8.77 \%$ of the capacity added in 2018 and $3.89 \%$ of total installed capacity, the near future prospects expect increasing offshore installations could reach $6 \mathrm{GW}$ or more installed annually [1]. In 2019, new offshore installations summed up to a record of $6.1 \mathrm{GW}$, amounting to $10 \%$ of the total capacity installed that year, and bringing the cumulative offshore capacity to more than $29 \mathrm{GW}$, representing $4.5 \%$ of the total wind power in the world [2].

Power electronics-based converters are an important part of wind energy conversion systems (WECS). In [3], wind energy-based power converter technologies are reviewed. The significant value added by variable speed operation is emphasized in literature. Variable speed operation allows a WECS to achieve the desired maximum power point operation. PMSGs and DFIGs have emerged as desirable generator architectures in WECS [4]. The B2B two-level VSC is a common topology for grid integration of PMSG-based WECS [4]. The GSC is responsible for injecting the desired active and reactive power into the grid, while maintaining a constant DC link voltage via sourcing the extracted power from the wind generator into the DC link.

Uncontrolled bridge rectifiers can be used with $\mathrm{AC}$ filters for AC-to-DC conversion on the WT side. The AC filters ensure operation with relatively undistorted stator currents, which reflects positively on both performance and lifetime of the generator. The AC filter requirements in B2B VSC-based WECSs are lower than the filtering requirements in the case of the uncontrolled rectifier-based system; this is due to the presence of low order harmonics in the latter [5]. Generally, to control the extracted power from WTs, stator currents should be controlled to ensure operation at an optimum mechanical rotating speed (speed at optimum tip speed ratio, or speed at maximum power point) [6].

In the case of offshore wind applications, wind energy is typically extracted and transmitted to onshore facilities via a HVDC transmission system to ensure operation with minimal transmission losses. Conventionally, WTs have limited output 
voltage (less than $1 \mathrm{kV}$ ) [7], thus a step-up transformer is typically used at the AC side of the WT [8], or a DC-DC boost converter is used to step up the rectified WT voltage [3], [8], and [9].

Parallel connection of WTs is needed when a high power wind power plant is envisioned [9]. For successful operation of a parallel WT-based energy conversion system, a wellregulated voltage is needed at the collection point. Due to wind speed variation, the generated voltage from each WT may differ. Conventional solutions employ full-rated regulating converters as in [7] and [10].

In this paper, a new concept is presented which utilizes full-rated uncontrolled rectifier bridges for AC-DC conversion, and partially-rated fully-controlled bridge rectifiers which are used as voltage tuners to guarantee flow of the desired maximum power point DC currents through the parallel connected branches. The advantages and drawbacks of the proposed system are highlighted in the conclusion. A simulation model for a two parallel WT system has been built to validate the concept.

\section{Principles of Wind Turbine Operation}

Wind is known as the natural phenomenon of atmospheric air in motion. The principle of wind power generation is based on the capacity of harnessing the energy associated with such motion [11]. Fig. 1 shows the basic setup and the fundamental physical variables involved in the process of harnessing wind power.

According to [12], the total power present on the wind can be written as in (1);

$$
P_{\text {wind }}=\frac{1}{2} \rho A u^{3}
$$

where $\rho$ is the air density in $\mathrm{kg} / \mathrm{m}^{3}, A$ is the area swept by the blades in $\mathrm{m}^{2}$, and $u$ is the wind speed in $\mathrm{m} / \mathrm{s}$. The mechanical power that can be harnessed by the wind turbine, however, is defined by [13] through the expression in (2);

$$
P_{\text {mech }}=C_{p}(\lambda, \beta) P_{w i n d}=\frac{1}{2} \rho C_{p}(\lambda, \beta) A u^{3}
$$

where $C_{p}$, the power coefficient, is a function of the blades' pitch angle $\beta$ and the tip speed ratio $\lambda$, which is given by (3);

$$
\lambda=\frac{\omega R}{u}
$$

where $\omega$ is the propeller's angular speed in $\mathrm{rad} / \mathrm{s}$ and $R$ is the rotor radius in $m$.

Betz's law [14] imposes that $C_{p} \leq \frac{16}{27}=0.593$, which limits the maximum power that can be taken from a moving mass of air to $59.3 \%$.

Wind speed suffers intense and continuous variations with time, and is usually modeled as a probabilistic process, such that the frequency at which the wind blows with certain intensity tends to follow a Rayleigh distribution [15].

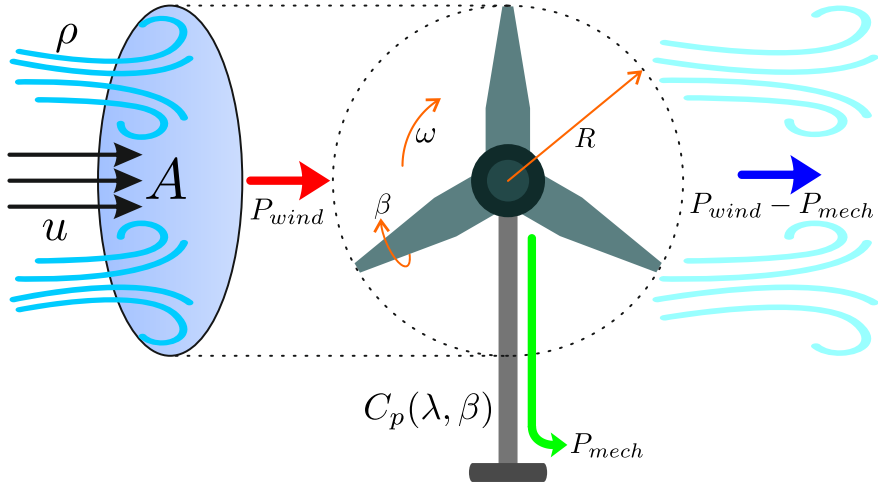

Fig. 1. Wind power harnessing principle

\section{PRoposed SYSTEM}

The proposed offshore WECS is shown in Fig. 2. The system consists of $N$ parallel connected WTs. The number of parallel connected WTs will be selected based on the desired overall system power and the rated power of each WT.

Most wind generators have an output voltage less than $1 \mathrm{kV}$. In the proposed system, the AC output of each WT is fed to a step-up transformer to step up the voltage to the transmission voltage level. The transformer output is fed to an uncontrolled bridge rectifier for AC-DC conversion. On the other hand, another partially rated step-up transformer is used with a lower voltage rating to feed a partially rated thyristorbased controlled rectifier. The main role of the thyristor bridge is to generate a controlled voltage which guarantees the flow of a desired maximum power point current by controlling thyristor firing angles. The thyristor bridge in the proposed system is able to operate in both rectification $\left(V_{T}>0\right)$ and inversion $\left(V_{T}<0\right)$ modes. Fig. 3 shows the branch current controllers and the approach for generation of firing angles for the thyristors. For a well-regulated branch current, a smoothing reactor is connected in series with the bridges as shown in Fig. 2.

The generator's output voltage and frequency will change accordingly to the wind speed. The operational frequency range must be taken into account to ensure effective design and tuning of $\mathrm{AC}$ filters and controllers. If due to low wind speed, any of the WTs has a low output voltage such that the thyristor bridge in its branch is unable to meet the desired specifications, the branch will be disconnected using the disconnects $\left(S_{1}, S_{2}, \cdots, S_{N}\right)$.

It should be noted that:

(i) The firing angles will continuously oscillate within a certain range to maintain the average branch current at the desired level. The branch reactor has the role of current smoothing, so a relatively high inductance will be needed, which will mainly depend on the operating voltage level.

(ii) The current of each branch is unidirectional, so if the desired branch voltage cannot be reached, the current of this branch will drop down to zero due to diode reverse bias. 


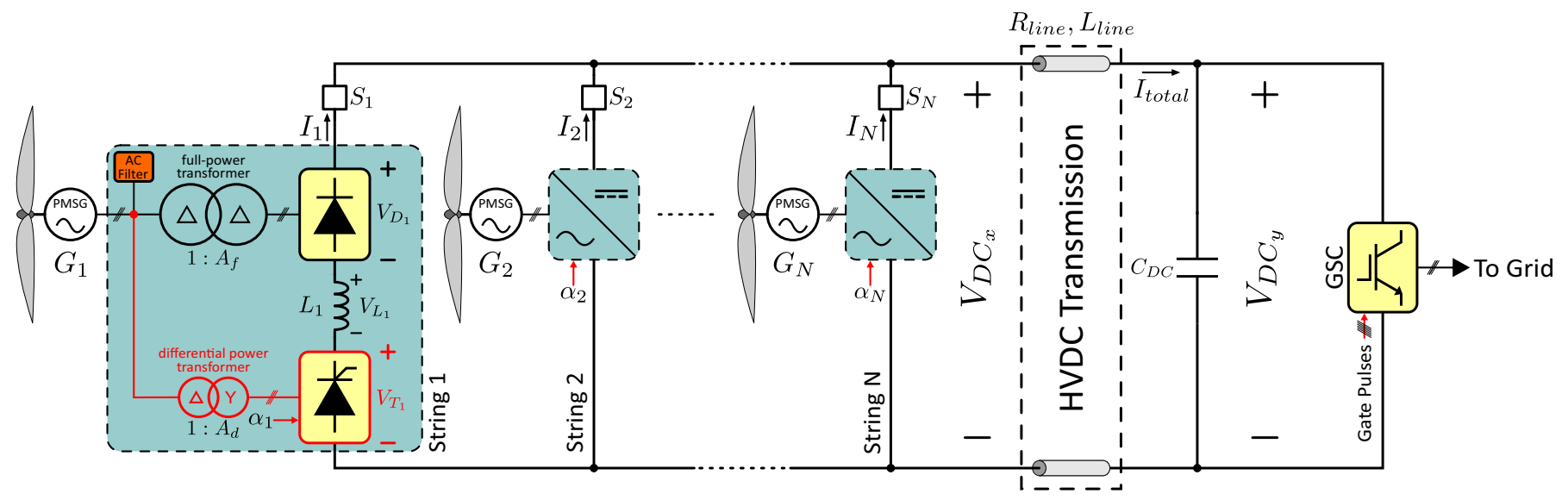

Fig. 2. Proposed offshore WECS

As shown in Fig. 2, all WT branches are connected in parallel, and energy is collected at a common voltage level $V_{D C_{x}}$. The power is transmitted through submarine HVDC cables to an onshore grid-connected converter. DC voltage control should be applied at the onshore grid-connected converter to ensure constant collection point DC-link voltage $V_{D C_{y}}$, i.e. absorbing all transmitted power from the WECS.

\section{Mathematical Modeling}

The following mathematical modeling is based on the proposed hardware configuration with $N$ parallel-connected WTs shown in Fig. 2. As all branches are connected in parallel, the current flowing through the HVDC transmission line can be written as in (4);

$$
I_{\text {total }}=\sum_{j=1}^{N} I_{j}=I_{k}+\sum_{j \neq k} I_{j}
$$

which is valid $\forall k \in[1, N]$.

The average power balance equation at the offshore side, given that the average voltage at each branch's smoothing inductor is zero, is given by (5);

$$
V_{D C_{x}} \sum_{j=1}^{N} I_{j}=\sum_{j=1}^{N} I_{j}\left(V_{D_{j}}+V_{T_{j}}\right)
$$

and the common point voltage $V_{D C_{x}}$ is given by (6).

$$
V_{D C_{x}}=V_{D C_{y}}+R_{\text {line }} \sum_{j=1}^{N} I_{j}+L_{\text {line }} \sum_{j=1}^{N} \frac{d}{d t} I_{j}
$$

The common point voltage can be also expressed for any branch $k \in[1, N]$ using (7);

$$
\begin{aligned}
V_{D C x} & =V_{D_{k}}+V_{T_{k}}+V_{L_{k}} \\
& =\frac{3 \sqrt{3}}{\pi} A_{f} V_{m_{k}}+\frac{3 \sqrt{3}}{\pi} A_{d} V_{m_{k}} \cos \left(\alpha_{k}\right)+L \frac{d}{d t} I_{k}
\end{aligned}
$$

where $A_{f}$ and $A_{d}$ are the transformer turns ratios as shown in Fig. 2, $V_{m_{k}}$ is the peak phase output voltage of generator number $k$, and $\alpha_{k}$ is the firing angle of the thyristor bridge connected to branch number $k$.

Combining equations (4), (6) and (7), the following dynamic equation can be defined for any branch $k$ by (8)

$$
\begin{aligned}
\frac{d}{d t} I_{k}=\frac{1}{\left(L_{\text {line }}-L\right)} & {\left[-R_{\text {line }} I_{k}+\frac{3 \sqrt{3}}{\pi} A_{f} V_{m_{k}}\right.} \\
& +\frac{3 \sqrt{3}}{\pi} A_{d} V_{m_{k}} \cos \left(\alpha_{k}\right)-V_{D C_{y}} \\
& \left.+\sum_{j \neq k}\left(R_{\text {line }} I_{j}+L_{\text {line }} \frac{d}{d t} I_{j}\right)\right]
\end{aligned}
$$

Let us now assume that in the proposed WECS, all branches are equipped with identical PMSGs with $p$ number of poles. We can define:

(i) the constant which approximately relates the optimum rotor mechanical speed given the wind speed as $K_{\omega / u}$ in $\mathrm{rpm} /(\mathrm{m} / \mathrm{s})$

(ii) the constant which approximately relates the maximum power point given the wind speed as $K_{P / u}$ in $M W /(m / s)$

(iii) the constant representing the peak phase voltage gain per unit rotational speed of the rotor as $K_{V / \omega}$ in $\mathrm{V} / \mathrm{rpm}$

such that for any generator $k \in[1, N]$, given its wind speed $u_{k}$, the maximum power point output reference can be estimated by (9)

$$
P_{k}^{*} \approx u_{k} K_{P / u}
$$

On the other hand, the expected rotational speed can be estimated by (10);

$$
\omega_{k} \approx u_{k} K_{\omega / u}
$$

which allows for the calculation of the output peak voltage (11);

$$
V_{m_{k}} \approx \omega_{k} K_{V / \omega}
$$


and frequency (12)

$$
f_{k} \approx \frac{p}{120} \omega_{k}
$$

\section{CONTROL System}

The control system for the proposed WECS system is divided into two main controllers, namely, offshore controllers, consisting of individual controllers for each thyristor bridge, and an onshore controller for the GSC. Their operation is illustrated and discussed in the following subsections.

\section{A. Offshore Controllers}

The wind speed of each wind turbine will be monitored to extract the power at which the turbine will operate at its maximum power point condition. This can be simply done by feeding the wind speed to a maximum power point tracker (MPPT) to generate the optimum power reference for each turbine as shown in Fig. 3. The MPPT function can be achieved effectively using a stored look-up table [16] which describes the relation between wind speed and maximum power point of the turbine, for example.

The extracted optimum powers are used to obtain the branch current references by dividing each of the extracted powers by the common point voltage $V_{D C_{x}}$ as shown in Fig. 3. Finally, each branch current reference is compared with its actual value, and the current error is fed to a PI controller to generate the suitable firing angle of the thyristor bridge.

The PI controller gains are tuned such that the dynamic response is satisfactory, while avoiding saturation of the actuator, since there are limits imposed on the firing angles in a Graetz bridge.

\section{B. Onshore Controller}

Based on Fig. 2, all the offshore branches are connected in parallel and energy is collected at a common voltage level $V_{D C_{x}}$. The power is transmitted through submarine HVDC cables to an onshore converter facility. A conventional DC voltage control scheme, such as that in Fig. 4 should be applied at the onshore grid-connected converter to ensure a constant DC-link voltage $\left(V_{D C_{y}}\right)$, i.e. absorbing all transmitted power from the WECS. This can be simply done by comparing the receiving end DC voltage with its reference value, and feeding the voltage error to a PI controller to generate the needed amount of active power which should be absorbed from the DC-link to maintain a constant DC voltage. Based on the extracted active power, reactive power reference, and onshore grid voltage, the grid current references can be simply generated. These are then fed to a current controller along with the actual values to obtain the suitable reference voltage for the GSC.

\section{Simulation}

A simulation model has been implemented using Simulink's Specialized Power Systems library for the case of two parallel WTs in order to validate the proposed concept with the settings presented in Table I.
The simulation is initialized with the DC link capacitor already charged to the desired reference voltage $V_{D C_{y}}^{*}$ of $40 \mathrm{kV}$, which is kept constant.

The PLL used to synchronize the thyristor's control is configured with Simulink's default parameters, with exception of the minimum detectable frequency that is adjusted in order to allow for the minimum generator frequency to be detected.

For the wind speed profiles shown in Fig. 5a, the corresponding optimum mechanical speeds and maximum power points of each branch are shown in Fig. $5 \mathrm{~b}$ and $5 \mathrm{c}$ respectively.

The generator's parameters listed in Table I allow for straightforward calculation of the machine's voltage and frequency for any wind speed in the operating range.

The reference current of each branch can be simply obtained as shown in Fig. 3 by dividing the maximum power point by the measured value of $V_{D C_{x}}$. The corresponding reference currents are shown in Fig. 6a. These currents are fed to to proportional PI as in Fig. 3 to extract the suitable firing angle for each thyristor bridge shown in Fig. 6b, which results in flow of the desired current through each branch, as seen in shown in Fig. 6c.

Voltages of the uncontrolled rectifiers, controlled rectifiers, and inductors are shown in Fig. 7a, $7 \mathrm{~b}$ and $7 \mathrm{c}$ respectively. The transmitted DC current (scale $1: 5$ ), as well as the sending and receiving end DC voltages are shown in Fig. 8. The perphase filtered AC currents of the synchronous generators are shown in Fig. 9a and 9b respectively.

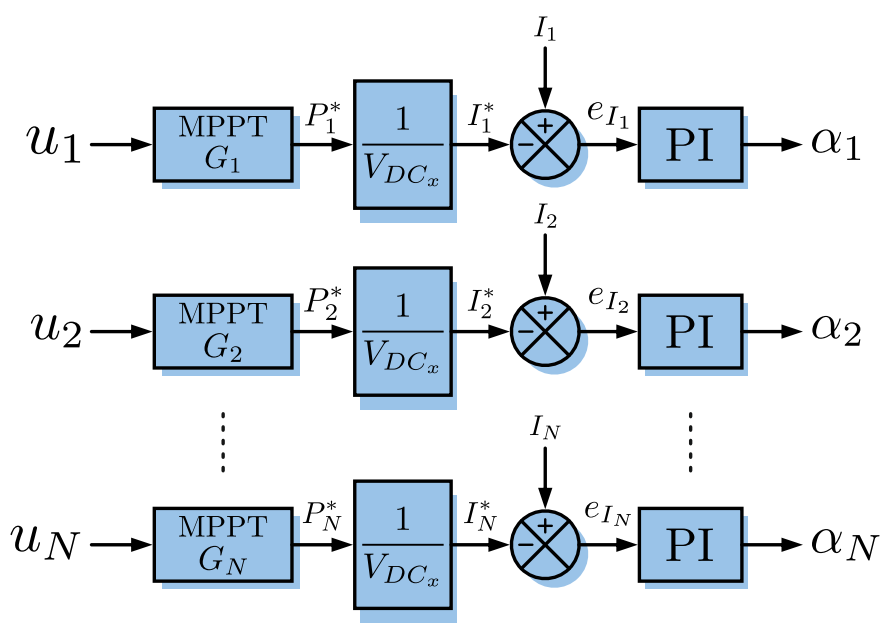

Fig. 3. Offshore controllers architecture

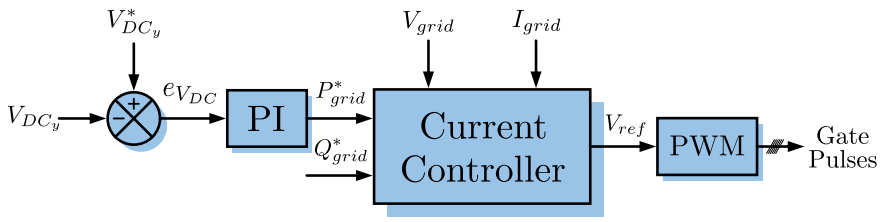

Fig. 4. Onshore controller architecture 


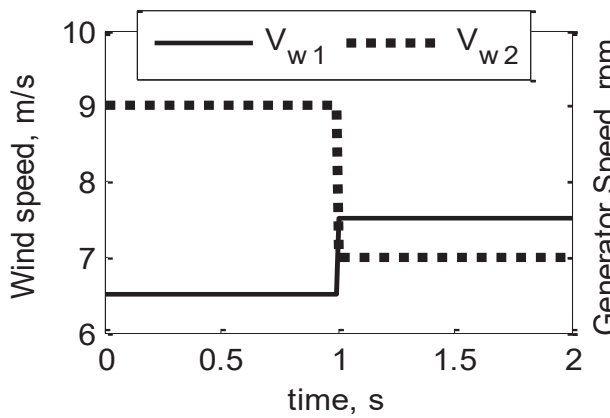

(a)

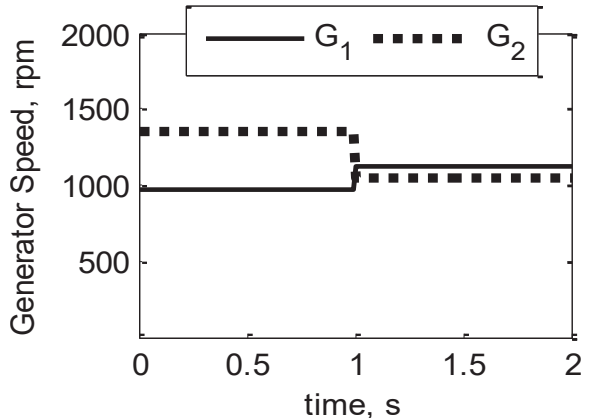

(b)

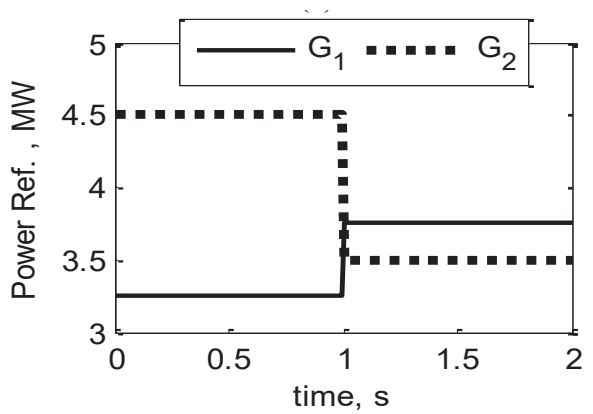

(c)

Fig. 5. (a) Wind speed profiles, (b) optimum rotor speeds, and (c) power references

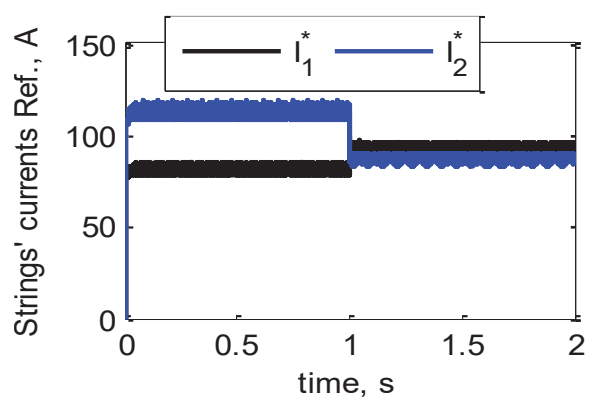

(a)

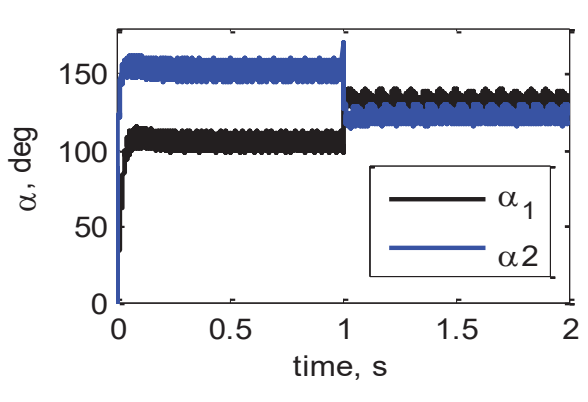

(b)

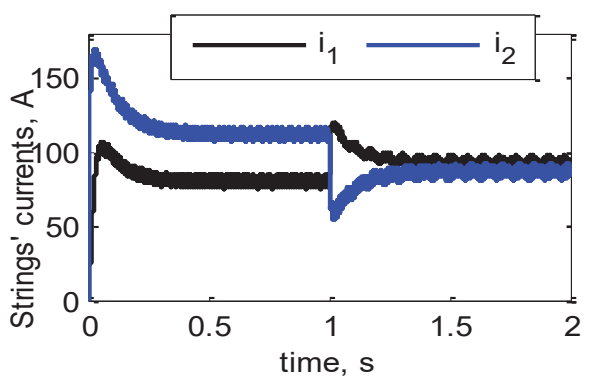

(c)

Fig. 6. (a) Optimum branches' currents, (b) thyristor bridges firing angles, and (c) branches' actual currents

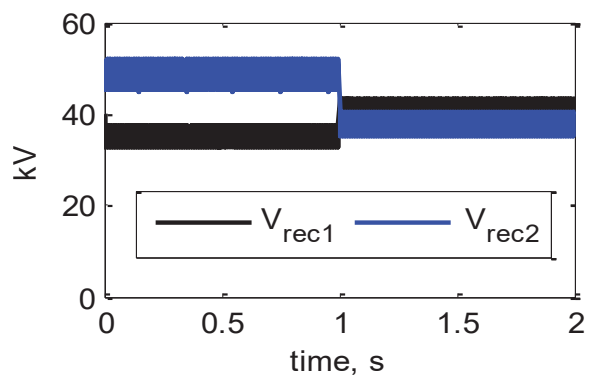

(a)

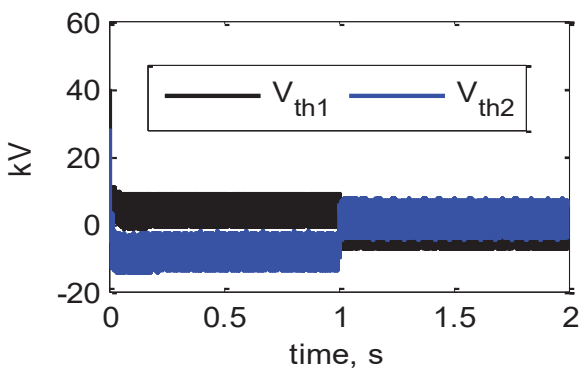

(b)

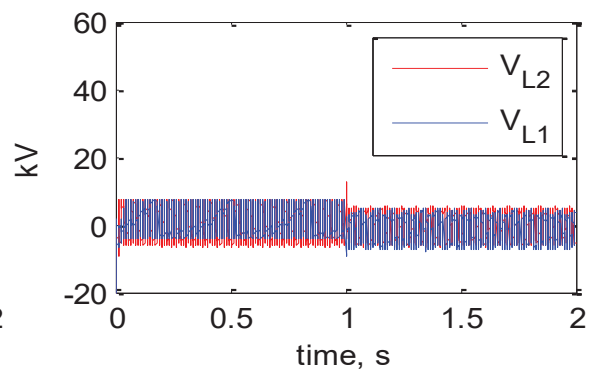

(c)

Fig. 7. (a) rectified voltages "diodes", (b) rectified voltages "thyristors", (c) inductors voltages.

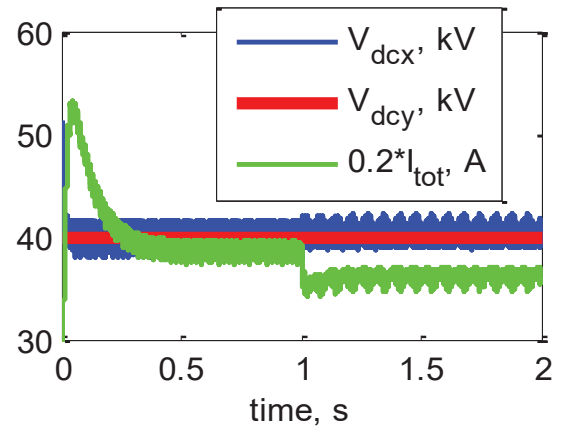

Fig. 8. Transmission side variables 


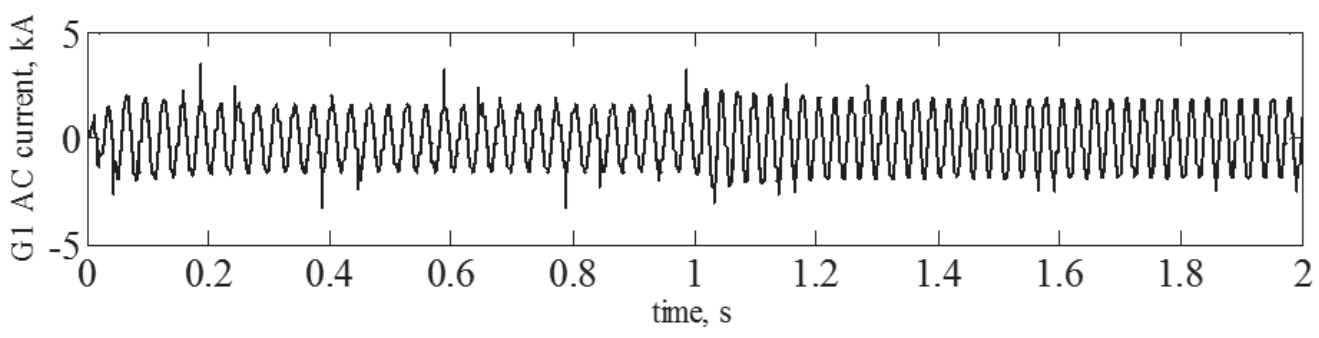

(a)

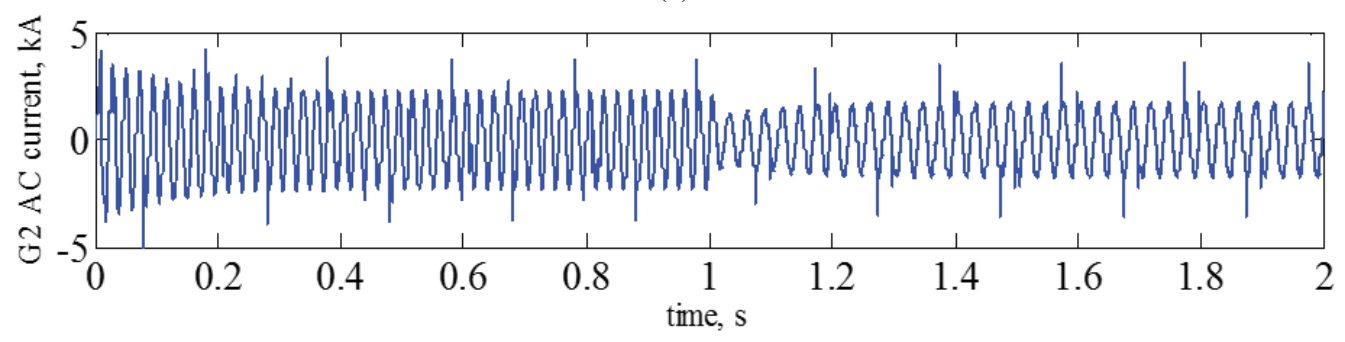

(b)

Fig. 9. Generators' currents, (a) AC Currents of G1 in $k A$, and (b) AC Currents of G2 in $k A$

TABLE I

Simulation MODEL DATA

\begin{tabular}{|c|c|c|}
\hline Component & Parameter & Value \\
\hline \multirow{10}{*}{ WT generator } & Cut-in wind speed & $6.5 \mathrm{~m} / \mathrm{s}$ \\
\hline & Rated wind speed & $10 \mathrm{~m} / \mathrm{s}$ \\
\hline & Rated voltage & $1 k V$ (RMS, phase) \\
\hline & Rated power & $5 M W$ \\
\hline & Rated speed & $1500 \mathrm{rpm}$ \\
\hline & Rated frequency & $50 \mathrm{~Hz}$ \\
\hline & & \\
\hline & $K_{P / u}$ & $\approx 0.5 \mathrm{MW} /(\mathrm{m} / \mathrm{s})$ \\
\hline & $K_{V / \omega}$ & $0.983 \mathrm{~V} / \mathrm{rpm}$ (Peak, phase) \\
\hline & $K_{\omega / u}$ & $\approx 150 \mathrm{rpm} /(\mathrm{m} / \mathrm{s})$ \\
\hline \multirow{2}{*}{ Transformers } & $A_{f}$ & 23.6 \\
\hline & $A_{d}$ & 6.67 \\
\hline Branch reactor & $L$ & $1 H$ \\
\hline \multirow{4}{*}{ HVDC } & $V_{D C_{y}}^{*}$ & $40 \mathrm{kV}$ \\
\hline & $C_{D C}{ }^{y}$ & $1 m F$ \\
\hline & $R_{\text {line }}$ & $0.5 \Omega$ \\
\hline & $L_{\text {line }}$ & $0.2 \mathrm{mH}$ \\
\hline \multirow{2}{*}{ Offshore PI } & $K_{p}$ & 0.025 \\
\hline & $K_{i}$ & 0.75 \\
\hline
\end{tabular}

\section{Design AND EXPERIMENTAl CONSIDERATIONS}

In order to reduce the harmonic content generated by the converters, transformers with different vector groups can be applied to each of the bridges. This is based on the same principle applied to 12-pulse converters. In the proposed system, the full-rated transformer is a $\Delta-\Delta$ (Dd0) and the partially rated is a $\Delta-Y$ (Dy1).

Due to the variability of the generator's output frequency, thorough analysis of the impedance profile of the AC filters is advised during the design process, in order to avoid parallel resonances that could amplify any harmonics generated along the whole operational frequency range.

The PLL employed to synchronize the thyristor gate pulse generator should have a lower bound on its detection set to less than or equal to the minimum generator frequency, i.e the frequency of the generator's output voltage at cut-in speed.

An experimental setup for a 2 parallel-connected WECS is suggested in Fig. 10 where for each branch, a three-phase variable auto-transformer feeds (optionally through an isolation transformer, for equipment safety) a diode full-bridge rectifier, while the Graetz bridge is fed through a fixed turns ratio stepdown transformer. A smoothing inductor is connected in series with the series, as in the original suggested topology in Fig. 2.

The thyristor control can be implemented by feedback of the measured branch current into a third-party software controlled SCR firing board. The transmission line electrical parameters are implemented as lumped elements and an electrolytic capacitor is added to the DC link.

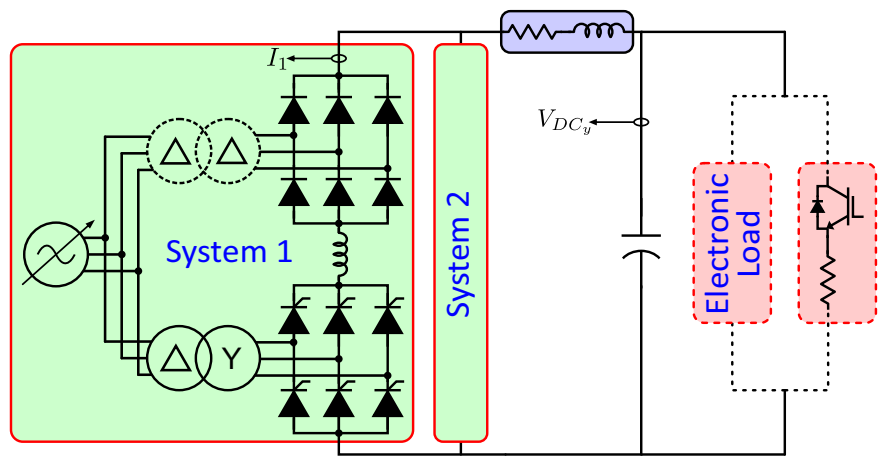

Fig. 10. Proposed setup for experimental validation 
The onshore side of the system can be simplified and emulated by a programmable DC load allowing for testing under different settings. Alternatively, a resistive DC load in series with a PWM controlled IGBT switch can be used to control the DC link voltage. The output of the variable transformers are modified in order to emulate wind speed changes, but preserving the constant utility frequency. Oscilloscopes and multimeters allow for measurement of any relevant electrical variables during the experiment.

\section{CONCLUSION}

In this paper, a new concept is presented for parallel connected WT systems which depends on using full-rated uncontrolled rectifier bridges for AC-DC conversion, and partially-rated controlled bridge rectifiers to tune the rectified voltages to guarantee operation at maximum power point for each wind turbine. The advantages of the proposed system are: its simplicity, cost effectiveness, reliability, and efficiency as it utilizes thyristors which will decrease the switching losses. The main drawbacks of the proposed system are the need for $\mathrm{AC}$ filters or VAR compensators at the AC side to ensure acceptable performance of the WT generator. On the other hand, smoothing reactors are needed on the DC side to produce a well-regulated DC current for shore facility transmission. A simulation model for a two parallel connected WT system has been built to test the proposed concept, and the simulation results validate the concept.

\section{ACKNOWLEDGMENTS}

Research supported in part by the Center of Excellence for NEOM Research at KAUST.

\section{REFERENCES}

[1] K. Ohlenfrorst, "GWEC Global Wind Report 2018," Wind Global Energy Council, Tech. Rep. April, 2019. [Online]. Available: www.gwec.net

[2] J. Lee and F. Zhao, "GWEC Global Wind Report 2019," Wind Global Energy Council, Tech. Rep. March, 2020. [Online]. Available: www.gwec.net

[3] F. Blaabjerg, M. Liserre, and K. Ma, "Power electronics converters for wind turbine systems," IEEE Transactions on Industry Applications, vol. 48, no. 2, pp. 708-719, 2012.

[4] M. Liserre, R. Cárdenas, M. Molinas, and J. Rodríguez, "Overview of multi-MW wind turbines and wind parks," IEEE Transactions on Industrial Electronics, vol. 58, no. 4, pp. 1081-1095, 2011.

[5] T. M. H. Nicky, K. Tan, and S. Islam, "Mitigation of harmonics in wind turbine driven variable speed permanent magnet synchronous generators," 7th International Power Engineering Conference, IPEC2005, vol. 2005, pp. 1159-1164, 2005.

[6] A. D. Hansen, F. Lov, F. Blaabjerg, and L. H. Hansen, "Review of contemporary wind turbine concepts and their market penetration," Wind Engineering, vol. 28, no. 3, pp. 247-263, 2004.

[7] J. Robinson, D. Jovcic, and G. Joós, "Analysis and design of an offshore wind farm using a MV DC grid," IEEE Transactions on Power Delivery, vol. 25, no. 4, pp. 2164-2173, 2010.

[8] K. Zhao, G. Li, B. Wang, and M. Zhou, "Grid-connected topology of PMSG wind power system based on VSC-HVDC," DRPT 2011 . 2011 4th International Conference on Electric Utility Deregulation and Restructuring and Power Technologies, no. 50877027, pp. 297-302, 2011.

[9] M. M. Amin, B. Mirafzal, and O. Mohammed, "A DC-bus voltage regulation for parallel wind-based synchronous generators," IECON Proceedings (Industrial Electronics Conference), pp. 3161-3166, 2010.
[10] C. Meyer, M. Höing, A. Peterson, and R. W. De Doncker, "Control and design of DC grids for offshore wind farms," IEEE Transactions on Industry Applications, vol. 43, no. 6, pp. 1475-1482, 2007.

[11] T. M. Letcher, Wind Energy Engineering: A Handbook for Onshore and Offshore Wind Turbines. Elsevier, 2017.

[12] C. Ng and L. Ran, Offshore Wind Farms: Technologies, Design and Operation. Elsevier, 2016.

[13] B. Fox, L. Bryans, D. Flynn, N. Jenkins, D. Milborrow, M. O’Malley, R. Watson, and O. Anaya-Lara, Wind power integration, 2nd ed. The Institution of Engineering and Technology, 2012, vol. 14.

[14] A. Betz, "Introduction to the Theory of Flow Machines," Introduction to the Theory of Flow Machines, 1966.

[15] P. Breeze, Wind Power Generation. Academic Press, 2016.

[16] Q. Wang and L. Chang, "An intelligent maximum power extraction algorithm for inverter-based variable speed wind turbine systems," IEEE Transactions on Power Electronics, vol. 19, no. 5, pp. 1242-1249, 2004. 